\title{
Development of Learning Media for Volleyball Subject Refereeing Subjects Based on Satellite E-Learning
}

\author{
Onyas Widianingsih ${ }^{1}$, Indrakasih ${ }^{2}$, Sinung Nugroho $^{3}$, Hardodi Sihombing ${ }^{4}$ \\ ${ }_{1,2,3,4}$ Universitas Negeri Medan, Indonesia \\ onyaswidia@gmail.com,kasihindra833@gmail.com,sinungnugroho5@gmail.com, \\ hardodisihombing@gmail.com
}

\begin{abstract}
This research is a research on the development of learning media for the subject matter of the Volleyball subject matter based on elearning satellite. This study discusses the role of learning media with technology. This study uses research from Borg and Gall through 10 stages including:(1) Preliminary Study, (2) Research planning, (3) Initial product development, (4) Initial (limited) field trials, (5) Revision of limited field test results, (6) wider field trials, (7) Revision of field test results, (8) Feasibility test, (9) Revision of feasibility test results, (10) Dissemination and socialization of final products. Results of this study: Small group test was carried out by testingdisplay of refereeing material Based on the value of the assessment questionnaire display of refereeing materialWith indicators of learning implementation assessment and material display, it is concluded that the questionnaire given to small groups has an effectiveness of implementing e-learning based refereeing learning by 55\%. In other words, there is still much that needs to be improved so that the application used can have maximum effectiveness in the effectiveness of the assessment questionnaire pimplementationrefereeing learning based on e-learning It can be concluded that the questionnaire given to IT and Media experts has a display pimplementationrefereeing learning based on e-learning $56 \%$.
\end{abstract}

Keywords learning media; volleyball; E-learning

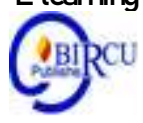

\section{Introduction}

Distance education has been developing since 1883. Along with developments in science and technology, the concept and implementation of distance education has also developed. Until now, distance education can be classified as having passed the fifth generation phase. The first generation of education still used correspondence services (correspondence). Along with the development of radio and television, distance education entered the second generation. Furthermore, with the invention of computers, distance education entered the third. The fourth and fifth generations are difficult to distinguish, because the fourth generation has used a combination of the first, second, and third generations, and the fifth generation has used an artificially based learning environment. This fifth generation is the future form of distance education.

The position of e-learning in distance education is a form of logical consequence, because of the separation of distance and time between learning participants and learning providers, it is absolutely necessary to learn based on information and communication technology (e-learning). Likewise, the independent learning system (independent lerning) is 
a logical consequence of distance education. So because of the separation of distance and time, distance education absolutely requires the application of independent learning systems and learning systems based on electronic technology (e-learning).

The effectiveness and efficiency of a media is an option in the implementation of the teaching and learning process which should be the goal of the teaching staff. However, in reality, there are still many lessons learned that have not led to what is needed. With the rapid growth of technology, the change from manual will be better by developing technological devices to support the effectiveness and efficiency of time in the learning process. The design that will be carried out in this research is the Development of Learning Media for the Subject of Volleyball Subject Surveillance Based on e-learning Satellite.

\section{Review of Literatures}

\subsection{Development Concept}

Research and development (Research and Development) according to Borg \& Gall is a process used to develop and validate products. There are many development research models that we can use, but in this discussion, we will briefly review development research using the Borg and Gall (1989) model. Borg and Gall's (1989: 784-785) version of the development research model includes ten activities, namely: (1) Preliminary Study (Research and data collection). (2) Research planning. (3) Initial product development. (4) Initial (limited) field trials, (5) Revision of limited field test results, (6) wider field testing, (7) Revision of field test results, (8) Feasibility test, (9) Revision of feasibility test results, (10) Dissemination and socialization of the final product.

\subsection{E-learning Technology and Media Used in Distance Education}

There are actually a lot of available technology and media options used in distance education. Holden (2005) mentions several technologies and media, both for synchronous and asynchronous learning, including e-learning satellites. This learning itself is distance learning, namely the delivery of learning and learning materials via internet protocol (IP) as a distribution network. In the Indonesian context, an example of satellite-learning is like that carried out by the directorate of higher education, namely the INHERENT (Indonesia Higher Education Network) program which utilizes the Virtual Private Network (PVN) or SEADUNET facilities carried out by SEAMOLEK.

In distance education, technology and learning media as mentioned above can be used for simultaneous learning from the time side even though the location is not the same (synchronous). There are several learning media used for learning simultaneously both in terms of time and location (asynchronous). Further, Holden (2005) summarizes the following.

Table 1. Variety of Media in Synchronous and Asynchronous Learning

\begin{tabular}{|c|c|c|}
\hline & Synchronous & Asingkronous \\
\hline Visual & & $\begin{array}{l}\text { - Corespondence (letter) } \\
\text { - Printerd media (print module) } \\
\text { - Recorded video }\end{array}$ \\
\hline Audio Only & Audio Conference & Audio recording \\
\hline Audio visual & $\begin{array}{l}\text { - Learning television / } \\
\text { satellite e-learning } \\
\text { - Video teleconferencing } \\
\text { - Synchronous web based } \\
\text { learning }\end{array}$ & $\begin{array}{l}\text { - Video recording } \\
\text { - Computer based learning } \\
\text { - Asynchronous web-based learning } \\
\text { - Learning television }\end{array}$ \\
\hline
\end{tabular}




\subsection{Definition of Media}

Before this description reaches the use of media by teachers in the teaching and learning process, it is better to understand what the media actually means. The word "media" comes from Latin and is the plural form of the word "medium", which literally means "intermediary or introduction". Thus, the media is a vehicle for channeling learning information or distributing messages.

According Sukiman in Prasasti ( 2019) said that learning media is anything that can be used to channel messages from the sender to the recipient so that it stimulates the thoughts, feelings, attention, and interests and wishes of students in such a way that the learning process occurs in order to achieve the learning objectives effectively. Meanwhile, according to Wiarto (2016: 3), "learning media is a learning tool used to convey information to students that aims to make students know". From this statement, the understanding of instructional media is described based on the objectives

Learning media is divided into 6 (six) types, namely: (1) Text; (2) Audio; (3) Visual; (4) Motion; (5) Real objects and models; and (6) People[1]. The most commonly used learning media is text-shaped media. This type of text media is used to convey learning material in the form of books, posters, whiteboards, computer screens and others. Other types of media that are often used as learning media are audio, including anything that can be heard, for example, human voice conversations, music sounds, mechanical engine sounds, and others. Visual type learning media are such as diagrams in a poster, images posted on walls (eg wall charts), pictures on a blackboard using chalk or markers, graphics in a learning book, photographs of objects, and others. Motion is a learning media in the form of motion such as videotape, film, and animation. Real objects or models are learning media in the form of three dimensions that can be touched and held by students. An example of a model-shaped learning media commonly used in vocational learning is "trainer"[4]. The last type of media is humans, namely teachers, students, or experts in their fields. Students can learn through teachers, fellow students, or to an expert in their fields. (Pratama et al, 2021)

If media is a source of learning, media can be broadly defined as people, objects, or events that allow students to acquire knowledge and skills. In the teaching and learning process, the presence of the media has quite an important meaning. Because in this activity the unclear material presented can be helped by presenting the media as an intermediary.

\section{a. Media as a Tool}

Humans can actually learn through six levels (Veron A. Magnesen), namely:

1. $10 \%$ of what is read

2. $20 \%$ of what is heard

3. $20 \%$ of what is seen

4. $20 \%$ of what is seen and heard

5. $20 \%$ of what is said

6. $20 \%$ of what is said and done

\section{b. Kinds of Media}

The media which has long been known today is not only of two types, but it is more than that. The classification can be seen from the type, coverage, and from the material and method of manufacture. All of this will be explained in the following discussion. 
Judging from its type, the media is divided into:

a. Auditive Media.

Auditive media is media that can only rely on voice capabilities, such as radios, cassette recorders, LPs ..

b. Visual Media

Visual media is a medium that only relies on the sense of sight, this visual media displays still images such as film strips (series films).

c. Audiovisual Media

Audiovisual media are media that have sound and image elements.

\subsection{Basic Considerations for Choosing Media Sources}

In order for the selected teaching media source to be appropriate, in addition to fulfilling the principles of selection, there are also several factors and criteria to consider as described below.

\section{Factors To Consider In Choosing A Media Source}

a) Objectivity

The element of teacher subjectivity in choosing teaching media must be avoided. This means that teachers should not choose teaching media on the basis of personal pleasure.

b) Teaching Program

The teaching program must be delivered to students in accordance with the applicable curriculum, both in content, structure, and in depth.

c) Program Goals

The program target in question is students who will receive teaching information through teaching media at a certain age level and in certain conditions, students have certain abilities, both in their way of thinking, their imagination, their needs, and their learning endurance.

d) Situation and condition

The existing situations and conditions also need attention in determining the choice of teaching media to be used. Situation and conditions as needed

\subsection{Volleyball}

According to Yunus (1992: 1) Volleyball is a team or team game for the purpose of entering the ball in the opponent's area through an obstacle in the form of a rope or net and trying to win the game by turning the ball off in the opponent's area. The role of volleyball is no longer just a recreational sport, but has developed into a part of educational sports and achievement sports or competitive sports.

Lenih continued Djoko Pudjihidajat in the journal Prasetyo (2015: 779) explained that volleyball is a team sport (Olympics) where two teams consist of 6 active players, each team is separated by a net. Each team tries to make a point by dropping the ball onto the opponent's court which is organized under the rules. Volleyball is a sport game that has many fans. To be able to play volleyball, mastering basic techniques includes passing, serving, smash and block. Technique is a way of doing or implementing something to achieve certain goals efficiently and effectively in accordance with the applicable game rules to achieve optimal results.

a. First Time Volleyball Game Rules

Apart from being an inventor, of course the rules in this volleyball game were also first made by William G. Morgan. He made a net 1.98 meters high and then put it in the middle of the field. The field size used was 7.6 meters $\times 15.2$ meters. In addition, there is also a 
duration in this volleyball game first, where each game or match consists of 9 sessions and with 3 services performed by each team and session.

b. Volleyball Game Rules

The field is divided into two equal playing areas, sometimes called the team area The volleyball court has a length of 18 meters and a width of 9 meters, and is divided into 2 areas so that each area becomes $9 \times 9$ meters. Each area has an attack line that is 3 meters from the middle. . The net for volleyball games has a height of 2.43 meters, while for women it is 2.24 meters.

\subsection{Rule of the Game}

The game starts with the toss of a coin to determine which team has the right to choose which course, or serve or not. After the opponent serves or gets a point, the one who does the serve switches by rotating clockwise. And so on. If there is an error rotation points will be awarded by the opponent.

The team can win the match if the team gets the 3 sets first. Each set consists of 25 points, except for the 5th set which has only 15 points, and before executing the 5 th set there is another toss of coins to choose which team can choose which course.

Time Out (TO) in volleyball game 2 on points 8 and 16, and each team has the opportunity to ask the referee 2 times TO in each set. Unless the 5th set occurs, TO is only held once at the 8th point, and each team has a chance of TO remain the same, which is 2 times.

- Each player on the field only 6 players, and each team must not be more than 12 players.

- Players must be in their respective positions, unless after the opponent has performed the service, the player may switch positions, only the back player may not jump in the attack area.

- The team serving or controlling the ball has the right to make 3 touches with different players, and if the team blocks and the block touches the ball, that does not count.

- The player can touch the ball with either body or two body parts simultaneously.

- The ball must not hit the body twice or for too long, because it is a foul.

- Players are not allowed to touch the net and step on the opponent's area. But body parts can loosen up over the opponent's area. Like when blocking, hands can stick out into the opponent's area.

\subsection{Draft Android Application that will be developed}

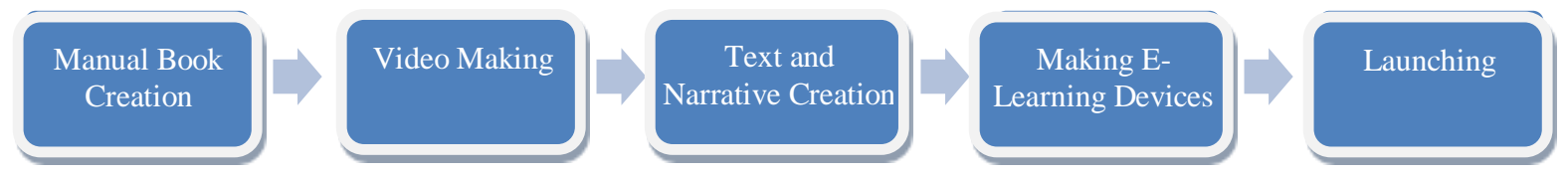

\subsection{Framework of Thinking}

The framework of thinking in this research is in the form of e-learning-based learning media development in a system which is a product in answering the needs of the teaching and learning process at the Faculty of Sports Science which has an impact on efficiency and is effective in using time. This media is expected to be able to help achieve maximum results in the final project bills for advanced volleyball courses. This product will also integrate with today's developments by utilizing the e-learning system which is a support system that will be used in e-learning-based satellite learning. 


\section{Research Methods}

This study uses research from Borg and Gall through 10 stages including: (1) Preliminary Study, (2) Research planning, (3) Initial product development, (4) Initial (limited) field trials, (5) Revision of limited field test results, (6) wider field trials, (7) Revision of field test results, (8) Feasibility test, (9) Revision of due diligence results, (10) Dissemination and socialization of final products

\subsection{Place and Time of Research}

The place where this research was conducted was at the Faculty of Sport Science, State University of Medan. The time of this research was conducted for one semester, namely in August - November 2020. This research only took the subject matter in the advanced volleyball subject.

\subsection{Data Collection Techniques and Data Analysis Techniques}

The research instrument used was an expert observation test, interviews, documentation and observation sheets. There are several data analysis techniques used, including descriptive analysis and inferential analysis. Data analysis in this development research used t test analysis technique.

\subsection{Research Instruments}

1. The instrument of this research was to use interviews about e-learning based instructional tutorial guides to volleyball refereeing experts

2. Using interviews in seeing the appearance of refereeing media to media experts about the display content of e-learning-based mediation material

3. Using interviews, which is what it is like to look for data through statements to students, what is the effectiveness of the e-learning-based refereeing video media can help in advanced volleyball course assignments.

\section{Result and Discussion}

\subsection{Effectiveness of Android-Based Data Processing Application Development}

The first stage of testing was carried out on 5 teaching teams. This section is tested on applications that have been made.

\section{a. Assessment Questionnaire}

1. Assessment Questionnaire refereeing learning based on e-learning

Assessment questionnaire refereeing learning based on e-learninghas 12 statement items. The results of the questionnaire assessment conducted by the volleyball teaching team can be seen as follows:

Small group test is done by testing display of refereeing materialby using two indicators. Based on the value of the assessment questionnaireInspection Material Appearancewith indicators of learning implementation assessment and material display with a questionnaire value of 32 with an ideal score of 61 with an effectiveness percentage of $51 \%$. As for the material display, the questionnaire value was 115 with an ideal score of 200 , the effectiveness was $58 \%$. For the overall indicator, the questionnaire score was 143 with an ideal score of 261 and the percentage was $55 \%$. So it is concluded that the questionnaire given to small groups has an effectiveness of implementing e-learning based refereeing 
learning by 55\%. In other words, there are still many things that need to be improved so that the applications used can have maximum effectiveness.

2. Processing Application Displayrefereeing learning based on e-learningThe first stage of testing was carried out on 3 IT and Media experts. This section is tested on the web that has been created.

\section{b. Assessment Questionnaire}

Processing Application Assessment Questionnaire refereeing learning based on elearning. Assessment questionnaire data processing development refereeing learning based on e-learninghas 12 statement items. The results of the questionnaire assessment conducted by IT and Media experts can be seen as follows: In the effectiveness of the assessment questionnaireimplementationrefereeing learning based on e-learning It can be seen that the assessment indicator of the test implementation and data processing of the questionnaire value is 17 with an ideal score of 38 and the percentage of its effectiveness is 53\%. As for the physical measurement assessment indicators, the questionnaire value was 69 with an ideal score of 117 with a percentage of $57 \%$. For the overall assessment indicators, the questionnaire value obtained a value of 88 with an ideal score of 156 with a percentage of $55 \%$. So it can be concluded that the questionnaire given to IT and Media experts has a displayimplementationrefereeing learning based on e-learning $56 \%$. In other words, there are still many things that need to be improved so that the application used can have maximum appearance / effectiveness.

Development Effectiveness Implementation refereeing learning based on e-learning. The second stage of testing was carried out on 10 people. This section was tested onrefereeing learning based on e-learningwhich has been revised based on the results of a questionnaire given to small groups. For large samples. For the effectiveness of the assessment questionnaireImplementation refereeing learning based on e-learning, the indicator for the assessment of the implementation of data learning has a questionnaire value of 117 with an ideal score of 122 and obtaining an effectiveness percentage of $96 \%$. As for the indicator of the display of refereeing material, the questionnaire value was 389 with an ideal score of 402 and the effectiveness percentage was 97\%. For all indicators, the questionnaire value was 501 with an ideal score of 522 with an effectiveness percentage of $97 \%$. In other words, the e-learning-based refereeing learning used is feasible to be used and marketed to the public.

\subsection{Display of Reviewing Materials}

The second stage of testing was carried out on 3 IT and Media experts. In this section, a test was carried out on the refereeing appearance that was revised in the first stage.

\section{a. Assessment Questionnaire}

\section{Questionnaire for Assessment of Android-Based Data Processing Applications}

Assessment questionnaire development of androit based volleyball athlete based sports talent scouting test data processing developmenthas 12 statement items. The results of the questionnaire assessment conducted by IT and Media experts can be seen as follows: For the effectiveness of the assessment questionnairerefereeing learning based on elearningIt can be seen that the questionnaire given to IT and Media experts for the assessment indicators of test implementation and data processing of the questionnaire value is 35 with an ideal score of 36 and the percentage of effectiveness is 57\%. For indicators of measuring the implementation of learning, the questionnaire value is 116 with an ideal score of 120 with a percentage of $57 \%$. For all indicators, the questionnaire score was 151 with an 
ideal score of 156 with a percentage of 57\%. In other words, the display of the material used is appropriate for use and marketed to the public. However, there are still a few more improvements that must be made before they are disseminated to the public.

\section{The effectiveness of the first stage of Android-based Data Processing Application Development}

Assessment of Supervision Material Display with learning implementation assessment indicators and material display with questionnaire values given to small groups has an effectiveness of implementing e-learning based refereeing learning by $55 \%$. In other words, there are still many things that need to be improved so that the applications used can have maximum effectiveness. While the questionnaire given to IT and Media experts has a display of the implementation of e-learning based refereeing learning by $56 \%$. In other words, there are still many things that need to be improved so that the application used can have maximum appearance / effectiveness.

\section{The effectiveness of the second stage of Android-Based Data Processing Application Development}

This section conducted trials on revised e-learning based refereeing learning based on the results of a questionnaire given to small groups for large samples. For all indicators, the questionnaire value was 501 with an ideal score of 522 with an effectiveness percentage of $97 \%$. The overall indicator score for the assessment questionnaire was 151 with an ideal score of 156 with a percentage of $57 \%$. In other words, the display of the material used is appropriate for use and marketed to the public. However, there are still a few more improvements that must be made before they are disseminated to the public.

\section{Conclusion}

Based on the results of field trials and the results of the researcher's discussion, it can be concluded that: Based on testing with small groups and large groups in providing basic satelite e-learning volleyball refereeing material, PJKR students can conclude that: Learning volleyball refereeing material based on satellite e-learning is better than conventional methods that have been applied in volleyball learning in refereeing material.

\section{Suggestions}

Based on the result research that has been state that "Development of Web-Based Basic Volleyball Learning Media for E-Learning Satellite-based Surveillance Materials. " already feasible and validated by sports experts, media experts and volleyball experts, then there are some suggestions as follows.

1. In the student learning process, lecturers can take advantage of "Development of Learning Media for Volleyball Learning Materials Based on Satellite E - Learning Physics, State University of Medan".

2. Students can take advantage of Satellite E - Learning for learning and practicing as much as possible.

3. Can conduct evaluations for lecturers of student activity in learning.

4. Provide space and time for students to study all volleyball refereeing material available on the web. 


\section{References}

Barbara L.Viera, Bonnie Jill Ferguson (1996) Volley ball steps to Sucses

Borg and Gall (1983). Educational Research, an Introduction. New York and London. Longman Inc.

Dewi Salma Prawiradilaga, Diana Ariani, Hilman Handoko (2013) Mozaik Teknologi Pendidikan E-learning edisi pertama. Penerbit. Kencana Prenadamedia Group.Rawamangun Jakarta 2013.

Holden, Joly T., Westfall, Philip j. -L.2005" An Instruction Media Selection Guide for Distance Education", United State Distance Learning Association (USDLA).USA: US-DLA official Publication

Nana Sudjana (1991:152) dalam strategi belajar mengajar penerbit Rineka Cipta

Prasati, T. et al. (2019). The Effectiveness of Learning Media Folklore Text of North Sumatera Based on Blended Learning by $10^{\text {th }}$ Grade Students of Vocational High SchoolHarapan Mekar-1 Medan. Budapest International Research and Critics in Linguistics and Education (BirLE) Journal. P. 480-490.

Pratama, Y. et al. (2021). Develop an Android-Based Learning Media Integrated with a Scientific Approach to the Colligative Solution's Nature. Budapest International Research and Critics in Linguistics and Education (BirLE) Journal. P. 322-329

Sugiyono. (2011). Metode Penelitian Kuantitatif, Kualitatif, dan R \& D. Bandung: Alfabeta. Yunus, M. (1992) n. Olahraga Pilihan Bola Voli. Surabaya: Unesa, Aplikasi Paikem. Yokyakarta 